\title{
Opportunities in the Mobile Search Market
}

José Luis Gómez-Barroso, National University of Distance Education, Spain

Claudio Feijóo, Technical University of Madrid, Spain

Ramón Compañó, Institute for Prospective

Technological Studies, Spain

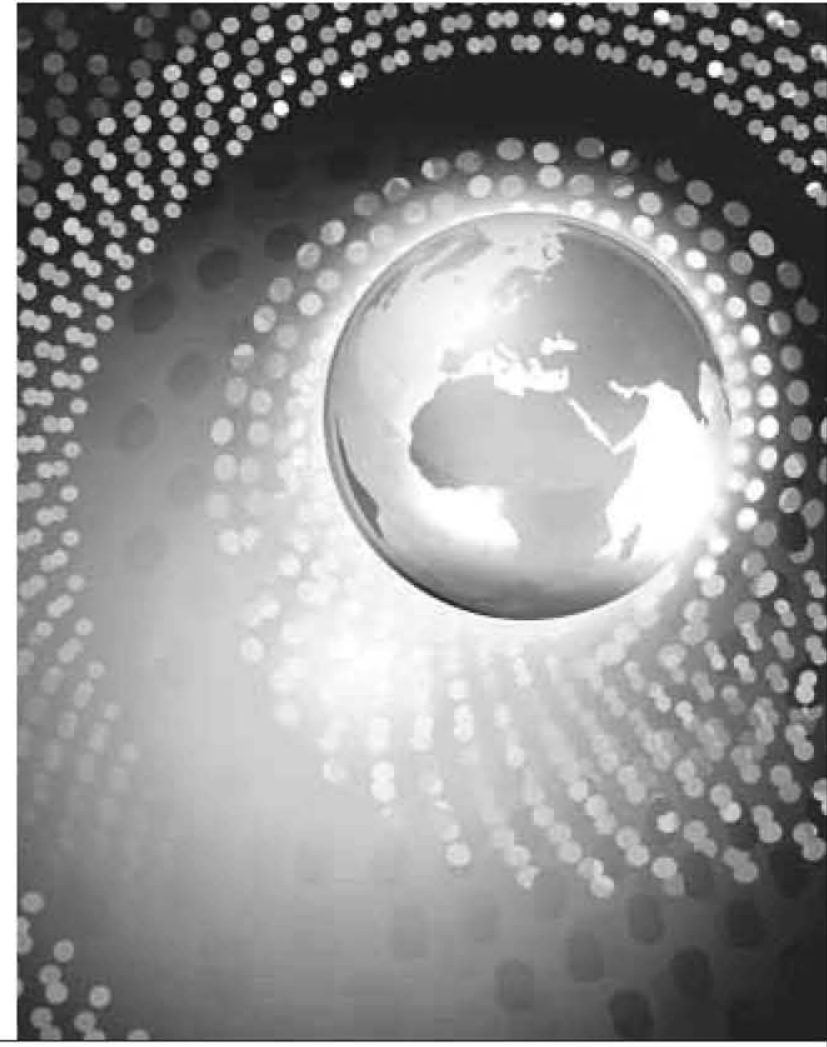

\section{Success in the mobile search market will come to those who provide value-added apps that exploit unique mobile functionalities, especially those related to personalized and context-based services.}

I

f the lessons of the desktopera fixed Internet experience hold, search engines will play a preponderant role in configuring mobile Internet markets. But as the dominant forces in the computer search market try to transfer their hegemony, they're quickly learning that mobile search must consider additional context variables unique to portable devices. Success isn't guaranteed to the field's current dominant players because mobile search opens up new options for creative applications.

\section{A SHIFTING BATTLEGROUND}

In April 2007, Google reached an agreement to acquire the online advertising company DoubleClick for US\$3.1 billion in cash. Acquiring DoubleClick expanded Google's influence far beyond algorithmdriven ad auctions into a relationshipbased business with Web publishers and advertisers. The Doubleclick buyout certainly isn't the sole factoror even possibly the primary one-in the company's evolution, but Google's revenues in 2008 were twice those in 2006, and the move expanded the company's dominance of the search engine market. Just three years later, in May 2010, Google invested $\$ 750$ million in the buyout of AdMob, a major mobile advertising platform that claimed to serve more than 8.5 billion mobile banner and text ads per month across thousands of mobile networks, websites, and applications.

Google's purchase of AdMob indicates that the battleground of the extremely lucrative network-provided applications and services markets is shifting. With an increasing number of users demanding ubiquity and permanent availability, the new scenario will undoubtedly become more mobile. But has the shift already happened?

Susan Wojcicki, vice president of product management at Google, gave some clues in a blog post she wrote following the AdMob acquisition: "Over the past two years, Google's mobile search volumes have grown more than fivefold, at an accelerated pace. In the first three months of 2010, people with smartphones with 'full' WebKit browsers (such as the iPhones, Android devices, and Palm Pre) searched 62 percent more than they did in the previous three months" (http://googleblog.blogspot. com/2010/05/weve-officially-acquiredadmob.html). Moreover, Eric Schmidt, 
former chief executive of Google, has mentioned several times since 2008 that Google can make more money in mobile than it can on the desktop.

All of this activity is impressive, but what's truly stunning is the first official statistical information on wireless broadband. In December 2010, the Organization for Economic Cooperation and Development released statistics on broadband penetration in OECD countries as of June 2010, reporting a wireless broadband indicator for the first time (www.oecd.org/sti/ict/ broadband). There were 294 million fixed broadband subscriptions but the number of mobile broadband subscriptions (those included in a mobile voice plan) and dedicated mobile data subscriptions (which require an additional data plan) totaled nearly 435 million.

In the fixed Internet, search engines serve as the access gate to all sorts of content and applications, providing those who control that access with a lot of power. For the mobile Internet, the strategy seems obvious: learn from history and repeat it. However, a series of circumstances makes a literal translation impossible. Success will come to those who provide valueadded apps that exploit unique mobile functionalities, especially those related to personalized and contextbased services.

\section{MOBILE SEARCH TECHNOLOGY}

At first glance, it might appear that mobile search is merely search on a mobile gadget. Adding some "mobility" enhancement function, such as refining results by taking into account the user's location or adapting them to the type of display, would still involve a search-as-usual strategy that extends the same desktop-based approach, systems, and algorithms to a new platform with specific features and limitations.

But in reality, mobile search should exploit contextual infor- mation, such as relevant data embedded in the mobile device, information in the surrounding environment, and the user's profiles or behavioral patterns, to improve search result relevance or to provide a more valuable and entertaining user experience. Such specificity could flourish in an environment in which hardware becomes "senseware," information coats objects and people, and ubiquitous locationaware social networks enhance the available information, sorting it on the user's behalf.

Search functionalities will be tightly embedded into the value chain of wider mobile services, which themselves can be numerous and complex.

In this scenario, mobile devices become the entry point to a networked environment in which "intelligence" is distributed across different elements. To make this vision a reality, three groups of technologies will likely have a direct impact on mobile search.

The first group comprises generic search technologies for retrieving accurate and enriched content. Such technologies could include semantic approaches, cognitive approaches, and multimedia retrieval.

The second group comprises specific mobile search technologies that would render mobile data acquisition-both its processing and its matching-more context aware or introduce augmented reality technologies to enrich context awareness.

Finally, the third group would include any technology components that can enable mobile applications. These would include wireless networks (broadband access ubiquity and dynamic spectrum management), sensor networks (RFID and Internet of Things), devices (multimedia capabilities, location, interoperability, and openness), and cloud computing (Web browsers, connectivity, security, and data protection).

\section{MONETIZING MOBILE SEARCH}

Interestingly, no significant bottlenecks seemingly stand in the way of introducing new mobile search applications from a technological viewpoint. Most of the building blocks are either already available or in an advanced prototype stage. The main difficulty lies in how to better integrate existing technologies.

That said, the real challenge will be how to monetize new mobile search applications. Advertising seems like a natural choice, particularly for search-as-usual applications; obviously, the strategies and formats must be adapted to the mobile environment.

Other sources of revenue are possible, but two basic factors will influence a new scheme's business model: the feasibility of monetizing the added value that mobile search provides within a given application, and the economic value of the search functionality.

Future search-based applications will neither be simple nor autonomous. Rather, search functionalities will be tightly embedded into the value chain of wider mobile services, which themselves can be numerous and complex. In technoeconomic terms, search functionality is a key constituent in an ecosystem in which industrial players compete or collaborate to generate successful and scalable business strategies in a highly dynamic and still emerging market landscape.

Additional factors must be considered when determining the sustainability of new types of mobile search ventures. First, the stakeholders are diverse and heterogeneous-device manufacturers, 
mobile network operators, infrastructure providers, mobile OS providers, Web search players, and mobilespecific search players all feature prominently. The variety of players, technologies, and approaches also complicates interoperability and increases transaction costs.

Second, this ecosystem is embedded in an institutional framework, so the success of search-based applications depends on regulatory environment factors, ranging from international data roaming costs to spectrum allocation issues to privacy regulations involved with personal data collection.

Data roaming in particular is relevant for search-based mobile applications because of the usefulness and innovative proposals it can offer to users on the move. International data roaming is slowly being solved regionally, with larger initiatives (some imposed by regulation, some originating in market forces) being introduced in Europe, Africa, and Asia.

Privacy regulation is a notoriously immature yet controversial issue. On one hand, privacy by design gives users control over their personal data through technology and contractual provisions; on the other, privacy protection requires a minimum set of mandatory rules to defend consumer interests. Depending on the country, users have very different privacy controls. US legislators have taken a utilitarian approach to data protection, whereas European legislators tend to define privacy as a fundamental right.

\section{WHAT IS THE MARKET SAYING?}

As mobile search expands rapidly and steadily, established players are taking up as much of the market as they can to help them evolve smoothly into offering new and smarter search technology as needed. Is it worth it for newer or smaller competitors to enter the fray? The field is certainly large enough: user demand for optin, highly personalized, location- and social-aware search services isn't yet satisfied.

Services aren't yet fully interoperable, don't link multiple dynamic databases, and don't morph according to context. Furthermore, current interfaces don't allow dynamic usage situations. Voice-, touch- and movement-based interfaces should seamlessly support users in accessing information in situations that change based not only on location but also on interactions with other

\section{Services aren't yet fully interoperable, don't link multiple dynamic databases, and don't morph according to context.}

devices, users, and available services as well as needs, activities, and preferences. Most of these possibilities remain commercially unexplored.

From the mobile business perspective, a secret war of uncertain result is under waymobile browsers versus mobile apps-in which the users are the unaware army. If the browser wins, mobile devices will become a convenient wireless extension of the fixed Internet, with advertising as the main financial model. If apps dominate, we'll see more valueadded innovations, but at the cost of fragmented solutions available for users - which could be either deviceor OS-dependent.

The two approaches have other differences as well. Application development appears to be more agile, but it's very dependent on the technoeconomic evolution of current platforms. Browser standards seem more stable, but browsers are better suited to cloud computing, which is much less defined.
$\mathrm{T}$ he challenge remains in bridging data and information needs and offering useful services that entice people to pay for them. Innovations are the key to fulfilling these expectations, and they depend on a conjunction of technological, economic, social, and regulatory aspects, along with a bit of luck - many of the most successful mobile industry apps have evolved from an initial user base in ways totally unforeseen by the apps' original designers.

In the case of mobile search, all these aspects are relevant, encompassing both hurdles and uncertainties. This is the daily scenario faced by innovators wanting to open up a space in the marketplace. [C]

José Luis Gómez-Barroso is a professor at the National University of Distance Education, Spain, and a PURC senior research associate, University of Florida. Contact him at jlgomez@cee.uned.es.

Claudio Feijoo is a professor at the Technical University of Madrid, Spain. Contact him at cfeijoo@cedint.upm.es.

Ramón Compañó is the program manager at the Institute for Prospective Technological Studies-Joint Research Centre of the European Commission. Contact him at ramon.compano@ ec.europa.eu.

Editor: Sumi Helal, Department of Computer and Information Science and Engineering, University of Florida; helal@cise.ufl.edu

Readers are encouraged to use the message board at www.computer. org/industry perspective to post comments, offer feedback, or ask questions.

cn Selected CS articles and columns are available for free at http:// ComputingNow.computer.org. 